Lifetime and damage threshold properties of reflective x-ray coatings for the LCLS free-electron laser

R. Soufli, M. Fernandez-Perea, S. P. Hau-Riege, S. L. Baker, J. C. Robinson, E. M. Gullikson, J. D. Bozek, N. M. Kelez, S. Boutet

May 9, 2011

Damage to VUV, EUV, and X-ray Optics Prague, Czech Republic April 18, 2011 through April 21, 2011 
This document was prepared as an account of work sponsored by an agency of the United States government. Neither the United States government nor Lawrence Livermore National Security, LLC, nor any of their employees makes any warranty, expressed or implied, or assumes any legal liability or responsibility for the accuracy, completeness, or usefulness of any information, apparatus, product, or process disclosed, or represents that its use would not infringe privately owned rights. Reference herein to any specific commercial product, process, or service by trade name, trademark, manufacturer, or otherwise does not necessarily constitute or imply its endorsement, recommendation, or favoring by the United States government or Lawrence Livermore National Security, LLC. The views and opinions of authors expressed herein do not necessarily state or reflect those of the United States government or Lawrence Livermore National Security, LLC, and shall not be used for advertising or product endorsement purposes. 


\title{
Lifetime and damage threshold properties of reflective x-ray coatings for the LCLS free-electron laser
}

\author{
Regina Soufli ${ }^{1 *}$, Mónica Fernández-Perea ${ }^{1,2}$, Stefan P. Hau-Riege ${ }^{1}$, Sherry L. Baker ${ }^{1}$, \\ Jeff C. Robinson ${ }^{1}$, Eric M. Gullikson ${ }^{3}$, John D. Bozek ${ }^{4}$, Nicholas M. Kelez ${ }^{4}$, Sebastien Boutet ${ }^{4}$ \\ ${ }^{1}$ Lawrence Livermore National Laboratory, 7000 East Avenue, Livermore, CA 94550, US \\ ${ }^{2}$ Consejo Superior de Investigaciones Científicas, C/ Serrano 144, 28006 Madrid, Spain \\ ${ }^{3}$ Lawrence Berkeley National Laboratory, 1 Cyclotron Road, Berkeley, CA 94720, US \\ ${ }^{4}$ SLAC National Accelerator Laboratory, 2575 Sand Hill Road, Menlo Park, CA 94025, US
}

\begin{abstract}
This manuscript presents a first study of the contamination observed on some of the $\mathrm{x}$-ray mirrors for the Linac Coherent Light Source (LCLS) free-electron laser, the implications to the mirror lifetime properties and an evaluation of candidate techniques towards successful recovery of these $\mathrm{B}_{4} \mathrm{C}$ - and $\mathrm{SiC}$-coated mirrors. Initial experimental results and plans for upcoming mirror recovery experiments are discussed. A summary of experimentally determined FEL damage thresholds of $\mathrm{B}_{4} \mathrm{C}$ and $\mathrm{SiC}$ materials is also given, and their wavelength dependence is discussed.
\end{abstract}

Keywords: free-electron lasers, x-ray optics, boron carbide, silicon carbide, damage, substrate recovery

\section{INTRODUCTION}

The world's first x-ray free-electron laser (FEL) facility, the Linac Coherent Light Source (LCLS) at the SLAC National Accelerator Center has been operational since 2009. Its unprecedented brightness, coherence, and resolution properties are already enabling groundbreaking discoveries in the fields of physics, materials and life sciences ${ }^{1}$. The LCLS emits 100 femtosecond monochromatic $x$-ray pulses of extremely high brightness $\left[10^{32}\right.$ photons $\sec ^{-1} \mathrm{~mm}^{-2} \mathrm{mrad}^{-2}(0.1 \%$ bandwidth) ${ }^{-1}$ ] in the 0.827 to $8.27 \mathrm{keV}$ photon energy region (in the $1^{\text {st }}$ harmonic) and is divided into two "branches": the soft x-ray branch, 0.827 to $2 \mathrm{keV}$ and the hard $\mathrm{x}$-ray branch, $2 \mathrm{keV}$ to $8.27 \mathrm{keV}$, which can be extended to $24 \mathrm{keV}$ if the $3^{\text {rd }}$ harmonic is used. At the exit of the LCLS undulators, in an area referred to as the Front End Enclosure (FEE), grazing incidence $\mathrm{x}$-ray mirrors are used as low pass-filters to spectrally and physically separate the coherent FEL beam (before it enters the experimental areas) from high-energy spontaneous radiation, bremsstrahlung, $\gamma$-rays and their secondary products. More specifically, a set of four soft x-ray mirrors are used in the FEE to direct the FEL beam to the soft X-ray materials science (SXR) and the atomic, molecular and optical science (AMO) experimental stations. A set of two hard $\mathrm{x}$-ray mirrors are used in the FEE to direct the FEL beam to the x-ray pump-probe (XPP), $\mathrm{x}$-ray photon correlation spectroscopy (XPCS), coherent x-ray imaging (CXI) and materials under extreme conditions (MEC) experimental stations. Moreover, the experimental stations are employing additional $\mathrm{x}$-ray optics as mirrors and gratings: two focusing mirrors are used at the AMO beamline, three mirrors and two gratings are used at the SXR beamline. In the hard x-ray branch, the CXI beamline uses two pairs of focusing mirrors and the MEC beamline uses one mirror. New experiments are also planned that will employ additional x-ray mirrors.

$\mathrm{B}_{4} \mathrm{C}$ and $\mathrm{SiC}$ were chosen as the reflective coating materials for the LCLS soft $\mathrm{x}$-ray and hard $\mathrm{x}$-ray optics respectively, due to their predicted high damage thresholds against the LCLS FEL beam compared to other coating materials, combined with the good reflective performance and absence of electronic absorption edges in the $0.827-2 \mathrm{keV}$ (for $\mathrm{B}_{4} \mathrm{C}$ in the soft $\mathrm{x}$-ray) and $2-24 \mathrm{keV}$ (for $\mathrm{SiC}$ in the hard $\mathrm{x}$-ray) energy ranges of operation. Our group at Lawrence Livermore National Laboratory (LLNL) has led a team composed of national laboratories and industry in the design, specification, fabrication, coating and precision surface metrology of all the $\mathrm{x}$-ray mirrors installed at LCLS, and these topics are discussed in detail in earlier references ${ }^{2,3,4,5,6,7}$. The $\mathrm{B}_{4} \mathrm{C}$ and SiC coatings of the LCLS x-ray mirrors were developed at

\footnotetext{
* e-mail: regina.soufli@llnl.gov, phone: 925-422-6013
} 
LLNL and were deposited by DC-magnetron sputtering ${ }^{8}$ on precisely figured and polished Si substrates supplied by commercial vendors.

Section 2 in this manuscript presents experimental data on the first observations of contamination on the surface of the LCLS x-ray mirrors currently in operation and explains the need to extend the lifetime of the LCLS mirrors and recover their original performance. Section 3 presents a summary of proposed mirror recovery strategies. Initial experimental data and work-in-progress on candidate recovery methods are also presented. Section 4 discusses experimentally determined FEL damage thresholds of $\mathrm{B}_{4} \mathrm{C}$ and $\mathrm{SiC}$ bulk and thin film materials, and their implications in the design of the LCLS x-ray optics. Section 5 is a summary and plans for future work.

\section{LIFETIME ISSUES OF LCLS X-RAY MIRRORS}

The AMO beamline was the first to become operational at LCLS in 2009, and has since been used in scientific experiments that are leading to exciting discoveries in the fields of atomic and molecular $\mathrm{x}$-ray physics ${ }^{9}$. After about 9 months in operation, a line-shaped blemish was observed by visual inspection on the $\mathrm{B}_{4} \mathrm{C}$-coated Kirckpatrick-Baez (KB) focusing mirror M2 at the AMO beamline. The blemish was located near the center of the mirror and had the shape of the footprint of the incident FEL beam. The appearance of the blemish, as seen by an optical profiling microscope, is shown in Figure 1. A set of two secondary blemish lines, not seen visually and located about $6 \mathrm{~mm}$ away from the center of the mirror in the saggital direction, were also revealed by the measurements and are shown in Figure 1. These secondary blemishes may have formed during alignment and testing of the mirror at the AMO beamline. Contact profilometry measurements using a Tencor P-11 $1{ }^{\mathrm{TM}}$ instrument on a YAG witness piece located upstream from the M2 mirror in the AMO beamline confirmed that the blemish was indeed a deposit (i.e. positive height), with a thickness varying between 15 and $38 \mathrm{~nm}$ (depending on location) on the main stripe. The actual M2 mirror blemish was not measured by contact profilometry, to avoid the risk of compromising the condition of the mirror reflective surface. To elucidate the nature of the blemish, Rutherford Backscattering (RBS) and X-ray photoelectron Spectroscopy (XPS) analysis of the blemish region on the witness YAG piece were performed at Evans Analytical Labs (Sunnyvale, California). RBS detected $100 \%$ carbon across $15 \mathrm{~nm}$ estimated blemish thickness. XPS was performed at 45 degrees take-off angle and showed atomic concentrations of $87 \% \mathrm{C}, 12 \% \mathrm{O}$ and $1 \% \mathrm{Si}$ across about $5 \mathrm{~nm}$ depth of information. Regarding chemical state, XPS found that the blemish was composed primarily of carbon species including hydrocarbon, O-containing organic species and possibly elemental carbon (e. g. graphite), while $\mathrm{Si}$ was found $\mathrm{as}^{\mathrm{SiO}} 2$.
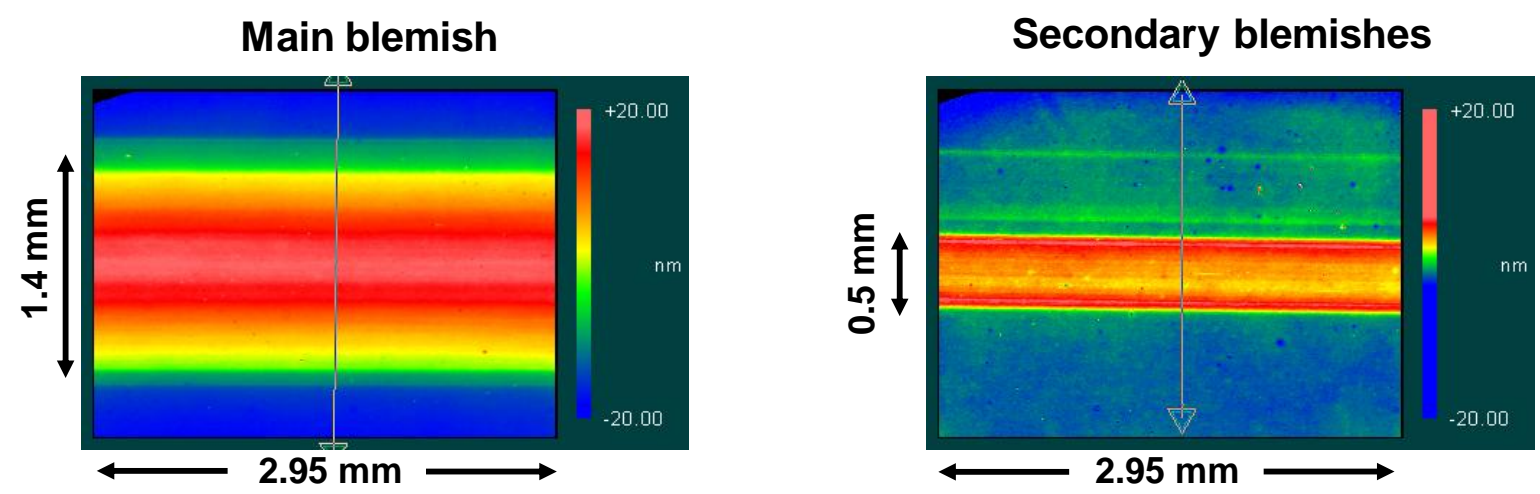

Figure 1: Optical profilometry measurements $\left(\mathrm{Zygo} \mathrm{NewView}^{\mathrm{TM}}\right.$ ) of the main (left) and secondary (right) blemish stripes obtained on the M2 KB focusing mirror at the AMO beamline. The horizontal direction in the images is the tangential direction on the mirror surface, and the vertical direction is the saggital. It should be noted that the optical profilometry instrument assumes the same index of refraction for the coated surface and "blemish" materials. If there is a significant difference between the two indices, then there is a corresponding error bar associated with the heights depicted in the measurements above. 
Similar blemishes have been observed on other $\mathrm{B}_{4} \mathrm{C}$-coated soft $\mathrm{x}$ ray mirrors at LCLS, including transport mirrors in the FEE and focusing mirrors at the beamlines. All of the LCLS mirrors could eventually be affected, including the SiCcoated mirrors installed at the LCLS hard x-ray branch. C-based deposits have been observed repeatedly on x-ray mirrors in other facilities such as synchrotrons and are attributed to the photon beam impact combined with environmental conditions. Although they may be mitigated, ultimately they cannot be avoided even in the lowest and cleanest possible vacuum conditions. The extremely high brightness of the LCLS FEL beam (about 10 orders of magnitude higher than $3^{\text {rd }}$ generation synchrotron sources) presumably makes the mirrors highly susceptible to the buildup of such C-based contamination on the reflective surface. It is expected that at some point the $\mathrm{C}$ blemish will degrade the mirror's reflective performance to an unacceptable level, especially the preservation of the coherent wavefront which is of the highest importance at the LCLS. A few re-alignment iterations of the FEL beam on the mirror will be possible before the entire clear aperture of the mirror is fully degraded. At that point the mirror would have to be replaced. Nevertheless, the mirrors could be saved if adequate recovery techniques were developed.

\section{MIRROR RECOVERY STRATEGIES AND FIRST EXPERIMENTAL RESULTS}

While considering appropriate strategies to recover the $\mathrm{B}_{4} \mathrm{C}$ - and SiC-coated mirrors at the LCLS after the beaminduced, $\mathrm{C}$-based surface contamination discussed in the previous Section, we organize the candidate recovery strategies into two main categories: A) Techniques that could remove the C-based blemish while preserving the $\mathrm{B}_{4} \mathrm{C}$ (or $\mathrm{SiC}$ ) reflective coating and $B$ ) techniques that could remove both the blemish and the reflective coating, and recover the $\mathrm{Si}$ substrate, which would then have to be re-coated. In option $A$, the main challenge is that $\mathrm{C}$ is a constituent of both the blemish that needs to be removed, and of the carbide reflective coating that needs to be preserved. Among the techniques considered within option $A$ are ultraviolet (UV)-ozone cleaning (also used widely to clean $\mathrm{C}$ contamination from synchrotron mirrors), and plasma cleaning techniques utilizing atomic hydrogen or atomic oxygen. The requirements for successful implementation of a cleaning technique in option $A$ would be to preserve the x-ray reflectance, FEL damage threshold and thickness uniformity of the reflective coating, and avoid any material growth (e.g: oxides), erosion, roughening and chemical reactions. Furthermore, if a technique within option $A$ were deemed successful, it would be highly desirable if it could also be implemented in-situ with the mirrors installed at LCLS. In option $B$, we considered release under-layers (that would be deposited underneath the reflective carbide coating and would be later used to remove the coating), and chemical etching. Finally, UV-ozone could also be considered as a candidate technique within option $B$ if one could demonstrate that it can be used to remove the entire reflective coating successfully. The requirements for successful implementation of a mirror recovery technique in option $B$ is the complete removal of the reflective coating and $\mathrm{C}$-based deposit, the preservation of the figure, roughness and composition of the Si substrate and the avoidance of material growth, substrate erosion and chemical reactions on the substrate. Among the disadvantages of recovery methods within option $B$ is the fact that they are not feasible in-situ and the need for re-coating of the $\mathrm{Si}$ substrate.

We began our investigation of recovery strategies by focusing first on the $\mathrm{B}_{4} \mathrm{C}$-coated, soft $\mathrm{x}$-ray LCLS mirrors. These mirrors were installed earlier, have been operational for a longer time and may thus need to be replaced sooner compared to the hard x-ray, SiC-coated LCLS mirrors. We first attempted to implement the UV-ozone cleaning technique using a commercial, low-pressure mercury UV lamp located at the Center for X-ray Optics at Lawrence Berkeley National Laboratory (LBNL). The lamp emits UV radiation at two wavelengths, 184.9 and $253.7 \mathrm{~nm}$, and uses oxygen from the air to simultaneously produce and decompose ozone to obtain oxygen atoms, which react with hydrocarbons to form volatile species $\left(\mathrm{CO}, \mathrm{CO}_{2}, \mathrm{H}_{2} \mathrm{O}\right)^{10}$. This technique was applied first on the $\mathrm{YAG}$ witness piece with the $\mathrm{C}$ blemish discussed in the previous Section. After 27 hours of UV-ozone exposure, the blemish was completely removed from the YAG surface, as verified by visual inspection. The next logical step would be to apply the same UV-ozone exposure on a $\mathrm{B}_{4} \mathrm{C}$-coated test sample with a $\mathrm{C}$ deposit, formed after exposure to LCLS FEL radiation. Since such a test sample was not available at that time, the 27-hour UV-ozone exposure was applied on a $100 \mathrm{~mm} \times 25 \mathrm{~mm} \mathrm{~B}{ }_{4} \mathrm{C}$-coated Si wafer piece, as-deposited (no blemish). The deposition parameters of the test $\mathrm{B}_{4} \mathrm{C}$ coating were identical to those of the $\mathrm{B}_{4} \mathrm{C}$ coating on the LCLS mirrors. The aim of this experiment was simply to observe the effect of UV-ozone exposure on the $\mathrm{B}_{4} \mathrm{C}$ coating, in order to understand what would ultimately be the effect on a $\mathrm{B}_{4} \mathrm{C}$-coated LCLS mirror, outside the blemished region. The following measurements and analysis were performed on the test sample before/after UV-ozone exposure:

(a) extreme ultraviolet (EUV) reflectance measurements at $91.84 \mathrm{eV}(13.5 \mathrm{~nm})$ at beamline 6.3.2. of the Advanced Light Source synchrotron, LBNL, to assess the film thickness, (b) x-ray reflectance measurements at beamline 6.3.2. to assess 
the reflective performance of the $\mathrm{B}_{4} \mathrm{C}$ coating at $900 \mathrm{eV}(1.38 \mathrm{~nm})$, one of the LCLS photon energies and (c) $10 \times 10 \mu \mathrm{m}^{2}$ and $2 \times 2 \mu \mathrm{m}^{2}$ Atomic Force Microscopy (AFM) measurements for the high-spatial frequency roughness $\sigma$ of the coating. The AFM instrument was a Digital Instruments Dimension $5000^{\mathrm{TM}}$, equipped with an acoustic hood and vibration isolation, resulting in a noise level of $0.03 \mathrm{~nm}$ rms. The AFM instrument is operated in tapping mode which measures topography in air by tapping the surface with an oscillating probe tip. The probe tips were etched silicon, with a nominal tip radius of 5-10 nm. Data from each of the $2 \times 2 \mu \mathrm{m}^{2}$ and $10 \times 10 \mu \mathrm{m}^{2}$ AFM scans were stored in a $512 \times 512$ pixel array. $\sigma$ was computed through power spectral density (PSD) analysis of the AFM data. The PSD was formed by first calculating a two-dimensional Fourier power spectrum of the height data in each of the AFM scans ${ }^{11}$ and the spectrum was then averaged azimuthally around zero spatial frequency to produce a PSD with purely radial spatial frequency dependence. This approach works well for quasi-isotropic surfaces. The root-mean-square (rms) roughness $\sigma$ is obtained by the expression

$$
\sigma^{2}=\int_{f_{1}}^{f_{2}} 2 \pi f S(f) d f,
$$

where $f$ is the spatial frequency, $S(f)$ is the surface PSD, and $f_{1}, f_{2}$ define the spatial frequency range of interest. For the high-spatial frequency roughness, where $f_{1}=5 \times 10^{-4} \mathrm{~nm}^{-1}$ and $f_{2}=5 \times 10^{-2} \mathrm{~nm}^{-1}, \sigma$ was computed according to eq. (1) by combining PSD curves from the $10 \times 10 \mu \mathrm{m}^{2}$ and $2 \times 2 \mu \mathrm{m}^{2}$ AFM scans.

The results from the reflectance and AFM measurements are shown in Figures 2 and 3, respectively. The 27-hour UVozone exposure appears to degrade the $\mathrm{B}_{4} \mathrm{C}$ coating roughness from $0.47 \mathrm{~nm}$ to $2.74 \mathrm{~nm} \mathrm{rms}$, as shown in Figure 3 , while the thickness of the coating appears to have been reduced from $54.8 \mathrm{~nm}$ (as deposited) to $20.5 \mathrm{~nm}$ (after exposure), as shown in Figure 2. The AFM-measured roughness shown in Figure 3 was used in the fits of the EUV reflectance data shown in Figure 2, and the results are self-consistent. The x-ray reflectance data in Figure 2 show a reduction in reflectance from 0.86 to 0.75 , measured at $900 \mathrm{eV}$ and 0.8 degrees, the angle of incidence of the LCLS soft $\mathrm{x}$-ray mirrors. The fits to the EUV and x-ray reflectance data were performed using the IMD software package ${ }^{12}$. RBS and depth-sputter XPS analyses were also performed on the sample after UV-ozone exposure to assess its atomic and chemical composition, and were compared with earlier RBS and XPS results from as-deposited $\mathrm{B}_{4} \mathrm{C}$ coatings. The RBS analysis revealed an overall atomic composition of $\mathrm{B}=58 \%, \mathrm{C}=30 \%$ and $\mathrm{O}=12 \%$. The same RBS analysis on an asdeposited $\mathrm{B}_{4} \mathrm{C}$ film gave $\mathrm{B}=74 \%, \mathrm{C}=20 \%$ and $\mathrm{O}=6 \%$. These results show that the coating became $\mathrm{C}$ - and O-rich after UV-ozone exposure. The XPS analysis revealed non-uniform composition across the film thickness after UV-ozone exposure, with the top $3 \mathrm{~nm}$ being $\mathrm{O}$-enriched as $\mathrm{B}_{2} \mathrm{O}_{3}$. To confirm the $\mathrm{B}_{4} \mathrm{C}$ coating thickness reduction observed after the 27-hour UV ozone exposure, a second $\mathrm{B}_{4} \mathrm{C}$-coated $\mathrm{Si}$ wafer piece (a half section of a 100-mm diameter $\mathrm{Si}$ wafer) with as-deposited coating thickness of $\sim 60 \mathrm{~nm}$ was exposed for 44 hours. The sample had a 5-mm wide un-coated strip across its center, which served as a "step" for contact profilometry measurements, to assess the thickness of the coating before and after exposure. AFM measurements were also performed on this sample before and after exposure. The results for the thickness $d$ and high-spatial frequency roughness $\sigma$ after 44 hours of UV-ozone exposure are shown in Figure 3. The $\mathrm{B}_{4} \mathrm{C}$ coating appears to be almost entirely removed, with measured thickness $d$ less than $1 \mathrm{~nm}$ and roughness $\sigma=0.6 \mathrm{~nm}$ rms. It is also interesting to note the evolution of high-spatial frequency roughness $\sigma$ of the $\mathrm{B}_{4} \mathrm{C}$ coating in Figure 3, from $0.47 \mathrm{~nm}$ rms (as-deposited) to $2.74 \mathrm{~nm} \mathrm{rms}$ when about half of the coating thickness has been removed, to $0.6 \mathrm{~nm}$ rms when the coating is almost entirely removed, the latter result showing that after 44 hours of exposure the residual $\mathrm{B}_{4} \mathrm{C}$ thickness is equal to the rms roughness. This experiment confirmed that $\mathrm{UV}$-ozone treatment can indeed remove a $\sim 55 \mathrm{~nm}$-thick $\mathrm{B}_{4} \mathrm{C}$ coating from the Si substrate and is thus a promising candidate for recovery of the Si substrates of the LCLS soft x-ray mirrors. Further experiments are planned to fully understand the mechanisms of the $\mathrm{B}_{4} \mathrm{C}$ coating removal. We currently believe that formation of $\mathrm{C}$ - and $\mathrm{B}$ - volatile compounds are possible mechanisms. Moreover, further work is needed to figure out how to remove completely the $<1 \mathrm{~nm}$ rms residual $\mathrm{B}_{4} \mathrm{C}$ coating from the Si substrate and ensure the process is scalable to the full size of the LCLS mirrors, which range from 175 to $450 \mathrm{~mm}$ in length.

In the case of the SiC-coated mirrors of the LCLS hard x-ray branch, we first attempted to employ atomic oxygen plasma cleaning as a candidate technique for removal of the $\mathrm{C}$ deposit, while preserving the rest of the $\mathrm{SiC}$ reflective coating. In this method, plasma generated atomic oxygen reacts with hydrocarbons to form volatile species $\left(\mathrm{CO}, \mathrm{CO}_{2}, \mathrm{H}_{2} \mathrm{O}\right)$, which are pumped away. Commercial devices employing this technique are available and have been used to remove hydrocarbon contamination from Si-capped EUV multilayer mirrors ${ }^{13}$. For our first experiments we employed a reactive 
glow discharge source available at Brookhaven National Laboratory (BNL), which has been used successfully in the past to clean similar C-based blemishes from $\mathrm{Au}$ - and Ni-coated synchrotron elements ${ }^{14}$. The samples used in our first experiments were $100 \mathrm{~mm} \times 25 \mathrm{~mm} \mathrm{SiC}$-coated $\mathrm{Si}$ wafer pieces, with coating properties identical to those of the $\mathrm{SiC}$ coatings of the LCLS mirrors. The first exposures to the BNL reactive glow discharge source resulted in roughening of the $\mathrm{SiC}$ coating from 0.18 to $0.44 \mathrm{~nm}$ rms and in incorporation of materials from the steel electrode and exposure chamber $(\mathrm{Fe}, \mathrm{Cr}, \mathrm{Ni})$ into the coating. The x-ray reflectance of the $\mathrm{SiC}$ coating was also degraded. We believe that $\mathrm{RF}$ power needs to be reduced and possibly other exposure parameters need to be optimized, in order to further explore the potential of this technique as a recovery candidate for the LCLS hard x-ray mirrors. Moreover, we plan to also explore hydrogen plasma cleaning as a candidate technique for LCLS mirror recovery.
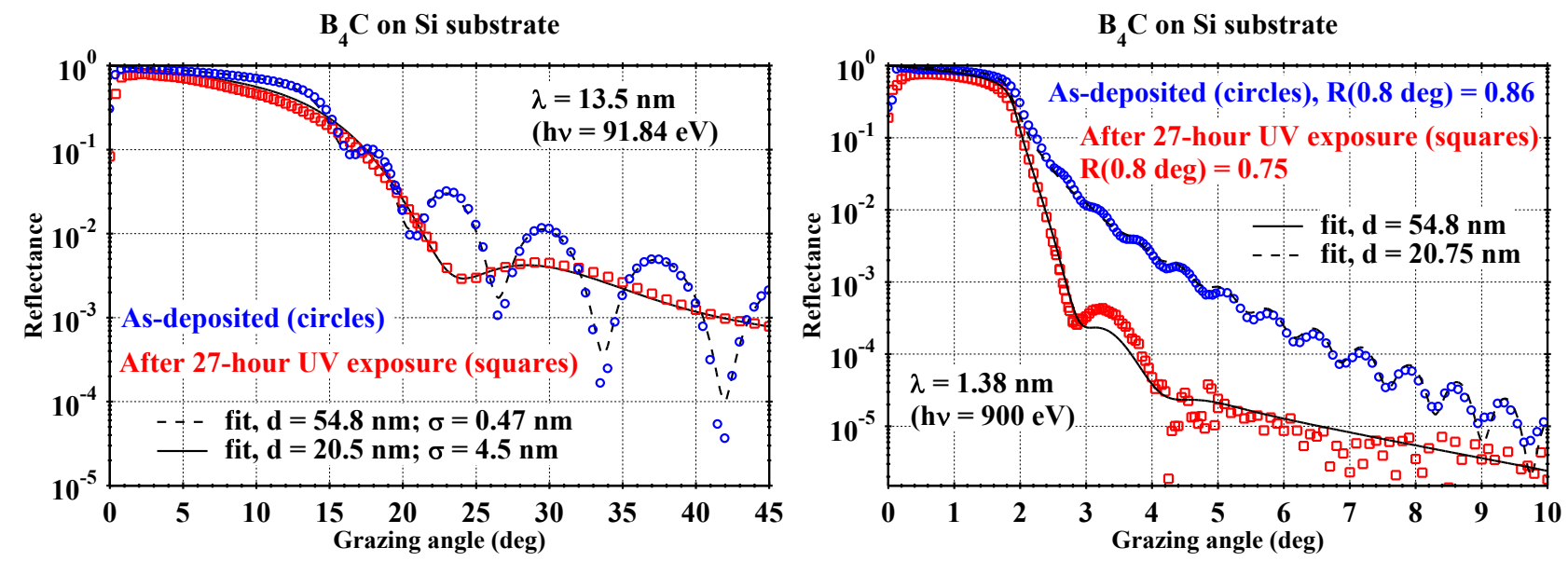

Figure 2: EUV (left) and $\mathrm{x}$-ray (right) reflectance measurements and fits from a $\mathrm{B}_{4} \mathrm{C}$-coated $\mathrm{Si}$ wafer, before and after UV-ozone exposure for 27 hours. The $\mathrm{B}_{4} \mathrm{C}$ coating thickness $d$ is fitted from the EUV reflectance measurements in each case.

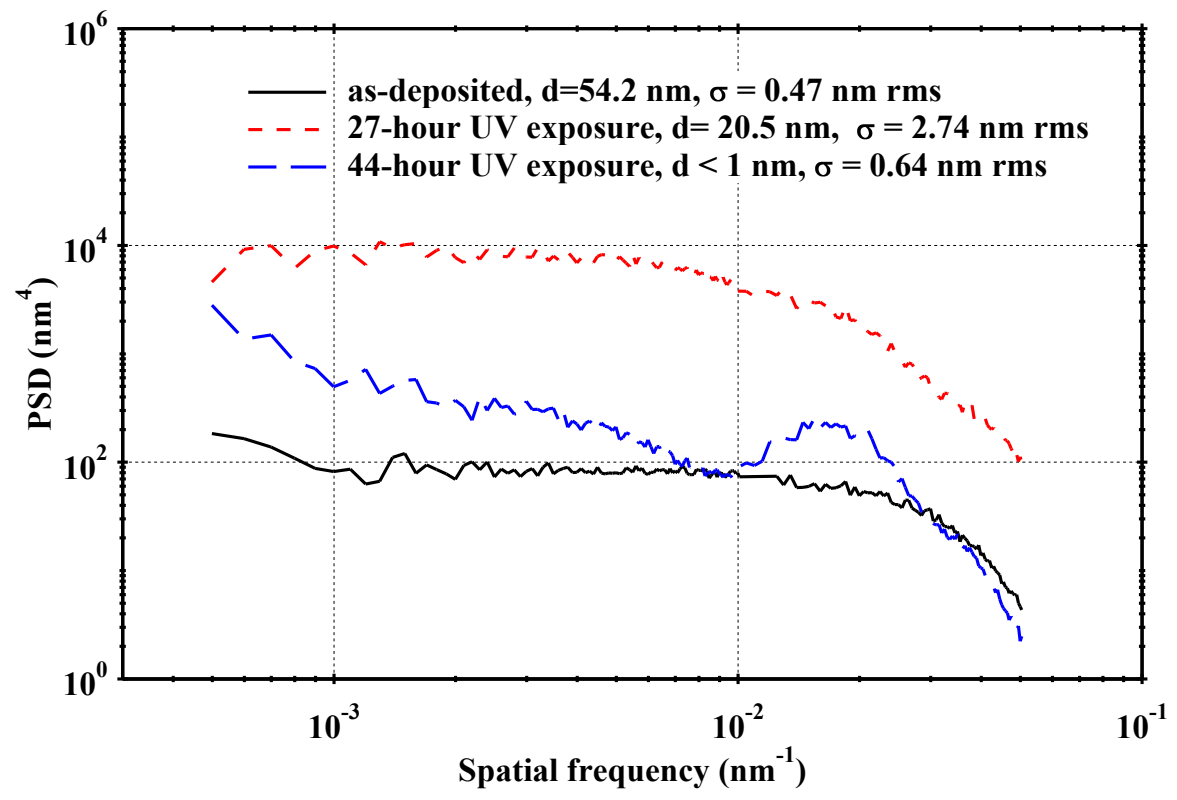

Figure 3: PSD curves and high-spatial frequency roughness $\sigma$ values derived from $2 \times 2$ and $10 \times 10 \mu \mathrm{m}^{2} \mathrm{AFM}$ data are shown for $\mathrm{B}_{4} \mathrm{C}$ coatings at different stages of $\mathrm{UV}$-ozone exposure. The thickness $d$ of each $\mathrm{B}_{4} \mathrm{C}$ coating, as determined through fitting of EUV reflectance data or through contact profilometry measurements, is also noted in each case. 


\section{FEL DAMAGE EXPERIMENTS}

To determine the experimental damage thresholds of $\mathrm{B}_{4} \mathrm{C}$ and $\mathrm{SiC}$ materials, several experiments spanning the photon energy range from $38.7 \mathrm{eV}$ to $830 \mathrm{eV}(32 \mathrm{~nm}$ to $1.5 \mathrm{~nm})$ have been performed at the LCLS and FLASH FEL

facilities ${ }^{15,16}$. The results are summarized in Figure 4 below. One trend that is apparent in Figure 4 is that the single-pulse FEL damage thresholds are somewhat higher for bulk than for films. This effect can be understood if one considers that the $1 \mu \mathrm{m}$-thick $\mathrm{B}_{4} \mathrm{C}$ and $\mathrm{SiC}$ magnetron sputtered films that were used in these studies have lower densities (90-95\% of bulk) and amorphous morphology ${ }^{7}$ compared to their bulk counterparts, which are crystalline. Another general trend that can be seen in Figure 4 is that the damage thresholds for both bulk and thin film $\mathrm{B}_{4} \mathrm{C}$ and $\mathrm{SiC}$ materials are close to the theoretically predicted damage thresholds, which justifies the principles used for LCLS optics design and materials selection $^{2,3,6,7}$. An important element to consider is the mechanisms that lead to damage in the photon energies of the FLASH vs. the LCLS FEL facilities. In the EUV energies at FLASH, photoionization processes involve mostly valence electrons excited into the continuum, and the radiation penetration depths are relatively shallow, leading to small interaction volumes of the FEL radiation with the material. Damage mechanisms in the EUV were thus found to be dominated by roughening, extrusions, and ablation processes, depending on energy dose. At the $\mathrm{x}$-ray energies of the LCLS FEL however, photoionization involves inner-shell electrons which are accompanied by Auger electron emission and local heating. Penetration depths are larger for the LCLS x-rays, leading to larger interaction volumes and mechanical damage which appeared as formation of severe cracks for example ${ }^{15,16}$. Further damage experiments are currently planned at both LCLS and FLASH FEL facilities, involving $\mathrm{B}_{4} \mathrm{C}$ and $\mathrm{SiC}$ materials in a variety of experimental configurations.
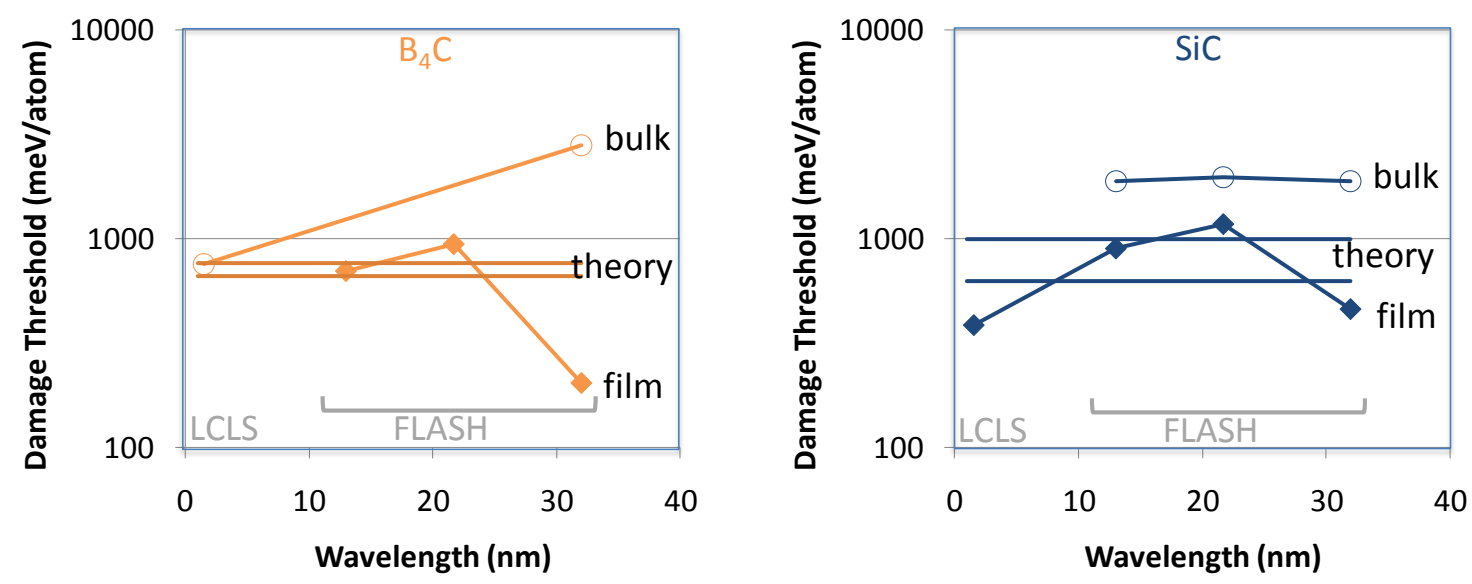

Figure 4: A summary of experimental damage thresholds of $\mathrm{B}_{4} \mathrm{C}$ (left) and $\mathrm{SiC}$ (right) is shown, for bulk (open circles) and thin films (solid points), obtained at normal-incidence, single-pulse mode at the LCLS and FLASH FEL facilities.

\section{SUMMARY AND FUTURE WORK}

Establishing the capabilities to recover the approximately $20 \mathrm{~B}_{4} \mathrm{C}$ - and SiC-coated LCLS x-ray mirrors after inevitable FEL beam-induced contamination should be a high priority. A survey of candidate techniques and initial experimental results indicate a few possible avenues towards recovering the LCLS mirrors. Additional experiments are planned to optimize these techniques and ensure they are successful and scalable to full mirror size. Experimental results at the LCLS and FLASH FELs demonstrate strong wavelength dependence of FEL damage thresholds and justify the selection of $\mathrm{B}_{4} \mathrm{C}$ and $\mathrm{SiC}$ as coating materials for the LCLS x-ray mirrors. 


\section{ACKNOWLEDGEMENTS}

We thank Thomas Fister, Bruce Rothman, Patrick Schnabel, Daniel Tseng, and Shannon Xia (Evans Analytical Group, Sunnyvale, California) for the XPS and RBS measurements. We are grateful to Paul Montanez for assistance with experiments. Financial support for Mónica Fernández-Perea was provided in part by Consejo Superior de Investigaciones Científicas (Spain) under the Programa I3P (Ref. I3P-BPD2004), partially supported by the European Social Fund.This work was performed under the auspices of the U.S. Department of Energy by Lawrence Livermore National Laboratory under Contract DE-AC52-07NA27344 and by the University of California Lawrence Berkeley National Laboratory under Contract No. DE-AC03-76F00098. Work was supported in part by DOE Contract DE-AC0276SF00515. This work was performed in support of the LCLS project at SLAC.

\section{REFERENCES}

\footnotetext{
${ }^{1}$ http://lcls.slac.stanford.edu/

2 M. Pivovaroff, R. M. Bionta, T. J. Mccarville, R. Soufli, P. M. Stefan, "Soft X-ray mirrors for the Linac Coherent Light Source", Proc. SPIE 6705, 670500 (2007).

${ }^{3}$ R. Soufli, M. J. Pivovaroff, S. L. Baker, J. C. Robinson, E. M. Gullikson, T. J. McCarville, P. M. Stefan, A. L. Aquila, J. Ayers, M. A. McKernan, R. M. Bionta, "Development, characterization and experimental performance of x-ray optics for the LCLS free-electron laser" Proc. SPIE 7077, 707716 (2008).

${ }^{4}$ R. Soufli, A. L. Aquila, F. Salmassi, M. Fernández-Perea, E. M. Gullikson, "Optical constants of magnetron sputtered boron carbide thin films from photoabsorption data in the range 30 to $770 \mathrm{eV",} \mathrm{Appl.} \mathrm{Opt.} \mathrm{47,} \mathrm{4633-4639} \mathrm{(2008).}$

${ }^{5}$ T. J. McCarville, P. M. Stefan, B. Woods, R. M. Bionta, R. Soufli, M. J. Pivovaroff, "Opto-mechanical design considerations for the Linac Coherent Light Source X-ray mirror system", Proc. SPIE 7077 70770E (2008).

${ }^{6}$ A. Barty, R. Soufli, T. McCarville, S. L. Baker, M. J. Pivovaroff, P. Stefan and R. Bionta, "Predicting the coherent Xray wavefront focal properties at the Linac Coherence Light Source (LCLS) X-ray free electron laser", Optics Express 17, 15508-15519 (2009).

${ }^{7}$ R. Soufli, S. L. Baker, J. C. Robinson, E. M. Gullikson, T. J. McCarville, M. J. Pivovaroff, P. Stefan, S. P. Hau-Riege, R. Bionta, "Morphology, microstructure, stress and damage properties of thin film coatings for the LCLS x-ray mirrors", Proc. SPIE 7361, 73610U (2009).

${ }^{8}$ R. Soufli, R. M. Hudyma, E. Spiller, E. M. Gullikson, M. A. Schmidt, J. C. Robinson, S. L. Baker, C. C. Walton, and J. S. Taylor "Sub-diffraction-limited multilayer coatings for the 0.3 numerical aperture micro-exposure tool for extreme ultraviolet lithography", Appl. Opt. 46, 3736-3746 (2007).

9 J. D. Bozek, "Ultrafast atomic and molecular photoionization at the LCLS", Proc. SPIE 8078, 8078-06 (2011).

${ }^{10}$ R. Soufli and E. M. Gullikson, "Reflectance measurements on clean surfaces for the determination of optical constants of silicon in the extreme ultraviolet-soft-x-ray region," Appl. Opt. 36, 5499-5507 (1997).

${ }^{11}$ D. L. Windt, "topo - surface topography analysis", available at http://www.rxollc.com/idl/index.html

${ }^{12}$ D. L. Windt, "IMD: Software for modeling the optical properties of multilayer films," Computers in Physics 12, 360370, 1998. Available at http://www.rxollc.com/idl/index.html

${ }^{13}$ C. G. Morgan, P. P. Naulleau, S. B. Rekawa, P. E. Denham, B. H. Hoef, M. S. Jones, R. Vane, "Removal of surface contamination from EUV mirrors using low-pressure downstream plasma cleaning”, Proc. SPIE 7636, 76361Q (2010).

${ }^{14}$ E. D. Johnson, S. L. Hulbert, R. F. Garrett, G. P. Williams, and M. L. Knotek, "In-situ reactive glow discharge cleaning of x-ray optical surfaces", Rev. Sci Instr. 58, 1042-1045, (1987).

${ }^{15}$ S.P. Hau-Riege, R.A. London, R.M. Bionta, D. Ryutov, R. Soufli, S. Bajt, M.A. McKernan, S.L. Baker, J. Krzywinski, R. Sobierajski, R. Nietubyc, J. B. Pelka, M. Jurek, L. Juha, J. Chalupský, J. Cihelka, V. Hájková, A. Velyhan, J. Krása, J. Kuba, K. Tiedtke, S. Toleikis, H. Wabnitz, M. Bergh, C. Caleman, N. Timneanu, ”Wavelength dependence of the damage threshold of inorganic materials under extreme-ultraviolet free-electron-laser irradiation", Appl. Phys. Lett. 95, 111104 (2009).

${ }^{16}$ S. P. Hau-Riege, R.A. London, A.Graf, S. L. Baker, R. Soufli, R. Sobierajski, T. Burian, J. Chalupsky, L. Juha, J. Gaudin, J. Krzywinski, S. Moeller, M. Messerschmidt, J. Bozek, and Ch. Bostedt," Interaction of low-Z inorganic solids with short x-ray pulses at the LCLS free-electron laser”, Optics Express 18, 23933-23938 (2010).
} 